\title{
Investigations of Brain Network Alterations in Epilepsy Using Functional Magnetic Resonance Imaging
}

\author{
Victoria L. Morgan and Bassel Abou-Khalil \\ Vanderbilt University \\ USA
}

\section{Introduction}

Epilepsy is a chronic condition characterized by recurrent unprovoked seizures with potentially disabling effects. These seizures, even when generated from a single focus, are believed to involve an extensive network of regions across the brain (Norden \& Blumenfeld 2002). The propagation across these networks is responsible for the complex events associated with seizures including altered consciousness and motor phenomena. Additionally, repeated seizures can also produce chronic deficits that persist in between seizures, mainly cognitive deficits, primarily of memory and language related functions (Helmstaedter, et al. 2003). It is likely that these cognitive effects can be related to measurable brain network alterations as well. The non-invasive quantification of alterations in brain networks related to epilepsy is critical in determining the mechanisms of epileptogenesis and its treatments. In addition, it may also identify imaging biomarkers of epilepsy which can be used to diagnose and monitor these patients.

Electroencephalography (EEG) is the most widely used method to quantify epileptic activity across the brain. The high temporal resolution of EEG measurements is advantageous in detecting the electrophysiological activity that defines the seizure focus and associated network. However, these techniques have relatively low spatial resolution when performed non-invasively, and can be corrupted by attenuation of the signal by bone or other tissue. Invasive EEG monitoring can measure electrical activity directly from the cortex, but the spatial resolution is still relatively low. The recording can only be obtained from preselected regions of the cortex. This method also involves more significant risk than non-invasive methods, but can be useful in detecting limited networks of epileptic activity (Blumenfeld, et al. 2004b, Englot, et al. 2008, Guye, et al. 2006).

Imaging methodologies make it possible to investigate networks across the whole brain without the need for identifying predefined regions. Some non-invasive, low spatial resolution techniques to detect epileptic networks include interictal positron emission tomography (PET) with [18F] fluoro-2-deoxy-glucose (FDG) (Cascino \& Jack 1996, Spencer \& Bautista 2000) and ictal single-photon emission computed tomography (SPECT) imaging (Cascino \& Jack 1996, Spencer \& Bautista 2000). In general, these methods attempt to detect regions of metabolic (PET) or perfusion (SPECT) changes during the interictal state or ictal events. Studies have detected widespread brain networks associated with seizures using 
these methods (Blumenfeld, et al. 2004a, Blumenfeld, et al. 2009, Wong, et al. 2010). One advantage of using ictal SPECT imaging is that different phases of the seizure can be probed in different seizures at different times (e.g. pregeneralization vs. post ictal) (Blumenfeld, et al. 2009). The disadvantages are that it requires injection of radiotracer at the time of the seizure prior to scanning and the spatial resolution is low. In addition, measurements cannot be made longitudinally with high temporal resolution in order to examine seizure propagation in the same event.

The objective of this chapter is to discuss how functional Magnetic Resonance Imaging (fMRI) can be used to examine brain network alterations in epilepsy. First, an introduction to the concepts of fMRI and functional connectivity will be presented. The main focus of the chapter will be a review of the current published work involving the investigations of changes in healthy resting-state brain networks caused by epilepsy and the identification of possible epileptogenic networks. In addition, the relationship of the network parameters to disease characteristics, diagnosis and treatment will be discussed in relation to the network alterations. Studies of quantification of causal influences across these networks using Granger causality and dynamic causal modeling will also be included. More novel methods of fMRI network analysis being applied to epilepsy will be described. Finally, the chapter will conclude with a brief overview of future research directions.

\section{Functional MRI and functional connectivity mapping}

Functional MRI is a widely used non-invasive neuroimaging technique that can detect and localize areas of the brain engaged in performing a specific task. This technique typically uses echo-planar image acquisition parameters that are sensitive to the changes in blood oxygenation occurring with neuronal activation (Blood Oxygenation Level Dependent or BOLD acquisitions) (Logothetis, et al. 2001, Ogawa, et al. 1990). Signal intensity in the BOLD images is increased when oxyhemoglobin concentrations increase due to neuronal activation. In conventional block-design fMRI studies, a series of images is collected during at least two different activation states (e.g. rest and stimulation) and their signal intensities are compared statistically on a voxel by voxel basis. The difference between these two image series indicates the location and intensity of neuronal activation in response to the given stimulation. In event-related fMRI, the images are collected following a repeated transient stimulus. Signal intensity following the stimuli is compared to the rest of the series. Therefore, in typical fMRI experiments, the timings of the various stimuli are known. The primary challenge in using fMRI in epilepsy is that interictal and ictal seizure activity is spontaneous and its timing cannot be controlled. There are two general approaches to attempt to overcome this problem. The first approach is to combine fMRI acquisitions with scalp EEG measurements (Gotman, et al. 2004). The EEG will provide the timing of the epileptic activity for conventional fMRI analysis. The second is to use a data-driven approach that identifies the interictal BOLD response in the fMRI data without EEG or other monitoring (Rodionov, et al. 2007).

Simple fMRI activation maps can determine the level of involvement of distinct regions of a network to perform a task at the time of acquisition. However, fMRI potentially can also reveal additional information about the functional coupling within this network using functional connectivity mapping. Functional connectivity uses linear correlations of low frequency $(<0.1 \mathrm{~Hz})$ fMRI BOLD signal oscillations usually at rest or during steady-state performance of a task (Rogers, et al. 2007). The resting state (awake with eyes closed) is a 
potentially interesting focus of attention because even at rest the brain accounts for approximately $20 \%$ of the total body oxygen consumption, primarily to maintain excitatory and inhibitory neurotransmission (Shulman, et al. 2004).

The two most commonly used methods of determining functional connectivity are seed based methods and independent component analysis (ICA). Both are based on temporal series of BOLD signals. The seed based approaches require the identification of a seed voxel or region, and the linear correlation across time of other voxels or regions to that seed is considered the measure of connectivity. This method is more suited for hypothesis testing due to its a priori identification of a seed. However, the most appropriate technique for defining a seed may be different for different applications. The ICA method attempts to transform the original data time series into individual components assuming that all of the signal sources and noise are statistically independent and are mixed linearly to create the observed signal. This technique has also been used successfully with fMRI data (Calhoun, et al. 2003, Moritz, et al. 2005). The advantage in applying these techniques to epilepsy is that all of the components of the signal (presumably from independent sources) are identified which can result in a large number of components. The primary disadvantages are (1) that these components will include many of those of no-interest due to shape or amplitude expectations, and separating the ones of interest becomes a significant task, and (2) the expected signal of interest may be relatively small.

\section{Networks defined in healthy controls}

There exists a set of functional brain networks that are consistently identified in the resting brain using fMRI time series data in healthy subjects. Typically these are identified as a group using an ICA analysis with varying numbers of components (Damoiseaux, et al. 2006, De Luca, et al. 2006). However, they can also be identified individually using seed region analysis of connectivity by placing a seed within an expected network (Biswal, et al. 1995, Xiong, et al. 1999), and also by using hierarchical clustering methods (Cordes, et al. 2002). While there are varying numbers of resting-state networks that have been described (based on varying degrees of specificity), they generally can be divided into approximately five overlapping spatial maps (De Luca, et al. 2006):

1. Visual cortex network- lateral and medial occipital cortex

2. Default-mode network - anterior cingulate, posterior cingulate, lateral inferior parietal cortex, hippocampus and prefrontal cortex

3. Sensorimotor and auditory network - pre and post-central gyrus, superior temporal gyrus, insula, thalamus and hippocampus

4. Dorsal pathway - lateral frontal regions and dorsal parietal cortex

5. Ventral pathway - lateral temporal, and inferior prefrontal cortex

These networks are reliable and reproducible within a scanning session and between sessions up to months apart (Zuo, et al. 2010). Several of these networks also seem to have unique electrophysiological signatures determined by EEG (Mantini, et al. 2007) and MEG (magnetoencephalography) (de Pasquale, et al. 2010) power. The networks similar to the visual, auditory and motor processing in adults have been detected in infants (Fransson, et al. 2007). This suggests the order of maturation of various networks in the brain, and may explain development of specific cognitive functions as a child ages. In order to understand how epilepsy and its treatment can affect normal cognitive function and behavior, it is useful to investigate the changes within the known resting-state networks of these patients. 


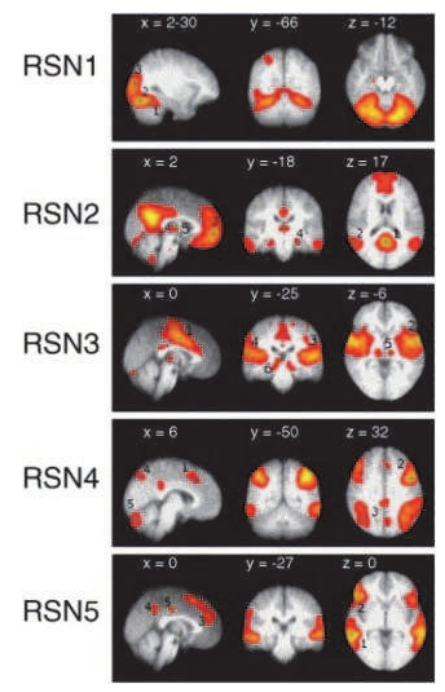

Fig. 1. Five resting state networks defined in healthy controls (Reprinted from NeuroImage, 29(4), De Luca, M et al., "fMRI resting state networks define distinct modes of long-distance interactions in the human brain" 1359-1367 (2006) with permission from Elsevier)

\subsection{Language and memory networks}

Chronic drug-resistant temporal lobe epilepsy (TLE) is associated with progressive memory impairment (Fisher, et al. 2000, Helmstaedter, et al. 2003) which is related to the structural damage of the epileptic hippocampus and other mesial temporal lobe structures in these patients (Kilpatrick, et al. 1997). In addition to the chronic epilepsy itself, the surgical treatment of TLE can also have a negative impact on language and memory functions. The fact that the seizures are generated from a specific focus in the mesial temporal lobe makes many drug-resistant mesial TLE patients good candidates for resective surgery. The success rate for seizure control following surgical resection is approximately $80 \%$ (Siegel 2004). In a randomized-control study of surgery vs. antiepileptic drug treatment for temporal lobe epilepsy, $58 \%$ of patients became seizure free with surgery vs. $8 \%$ on drug therapy (Wiebe, et al. 2001). The resulting seizure control can result in a significant increase in quality of life in these patients including employment or school attendance (Wiebe, et al. 2001). However, further declines in verbal memory and word finding after respective surgery to treat seizures are side effects occurring in as many as $40 \%$ of TLE patients (Langfitt \& Wiebe 2008). If severe, these impairments can affect the individual's ability to perform in work and social situations. Langfitt et al. reported that in patients with good seizure outcome, quality of life improved even if some memory loss occurred; but, in patients without post-surgical seizure control, quality of life decreased when memory loss occurred (Langfitt, et al. 2007). These findings illustrate the importance of quantifying and understanding these cognitive functions, and using this information to accurately predict the risk of cognitive decline after resective surgery. It is likely that these impairments, both before and after surgery, involve alterations in long-range networks in language and memory. Functional MRI provides a way to probe the functional integrity of these networks, and allows quantification of the relationships between cognition and connectivity in order to address these issues. 
To assess the utility of fMRI for prediction of post-surgical language and memory function, it must first be compared to the Intracarotid Amobarbital Test (IAT or Wada test) which was first developed by Wada in 1949. This test is used to determine hemisphere dominance for language and memory by an intra-arterial injection of an anesthetic agent to one hemisphere of the brain at a time while evaluating the patient's ability to perform language and memory tasks. The development of aphasia after injection indicates hemisphere dominance for language, and the lack of memory encoding suggests that the contralateral hippocampus cannot sustain memory function. The Wada test is an invasive and uncomfortable procedure with serious potential risks including carotid artery dissection, infection and stroke. One study reported almost $11 \%$ of patients had complications with $0.6 \%$ having residual deficits after three months (Loddenkemper, et al. 2008). In addition to risk, the cost of the Wada test can be high relative to fMRI (Medina, et al. 2004). Furthermore, even when successful, the Wada test lateralizes, but does not localize language and memory functions and their associated networks. As a result, the use of the Wada test in the presurgical evaluation of all TLE patients is decreasing (Baxendale, et al. 2008), while other non-invasive methods including fMRI are gaining acceptance (Abou-Khalil 2007, Pelletier, et al. 2007).

Functional MRI has been very successful for lateralizing language dominance as well as identifying and localizing language networks. There is a wide variety of stimulation tasks used for this purpose. Some of the more widely used tasks include word generation (Deblaere, et al. 2002, Ramsey, et al. 2001) for activating the inferior frontal language regions (Broca's Area), and tasks such as reading (Gaillard, et al. 2002, Rutten, et al. 2002b) and listening to speech (Binder, et al. 2008b, Bookheimer 2007) for identifying temporoparietal language regions (Wernicke's Area). The literature on this topic is vast, describing other potentially useful tasks. The concordance of these protocols with Wada test results is over $70 \%$ in many of these studies, but may be less in patients with atypical right-sided or bilateral dominance by Wada test. The combination of multiple fMRI tasks has been found to be more accurate than a single task (Arora, et al. 2009, Deblaere, et al. 2002, Ramsey, et al. 2001, Rutten, et al. 2002a), and these methods can also be modified for use in children (Arora, et al. 2009, Gaillard, et al. 2002). For these reasons, fMRI, when available, is quickly becoming the preferred technique for determining language lateralization and localization.

While the use of fMRI for language lateralization is gaining widespread acceptance, the assessment of memory functions with this method has been slower to develop. Some reasons for this disparity include the fact that fMRI memory paradigms are generally more complicated and require more trials to provide detectible signal changes than language paradigms. Also, the material being encoded in memory tasks can have a lateralizing effect itself (verbal vs. visual stimuli), (Golby, et al. 2001), and the interaction of this effect with the epilepsy can be difficult to interpret. Thus, memory paradigms have shown mixed success in lateralizing memory function in TLE compared to the Wada test (Deblaere, et al. 2005, Golby, et al. 2002, Jokeit, et al. 2001).

Some fMRI memory paradigms designed to activate the mesial temporal structures have been used with varying levels of success to predict post-surgical memory declines (Frings, et al. 2008b, Rabin, et al. 2004, Richardson, et al. 2006, Wagner, et al. 2007). Their general finding was that increased fMRI activation in the mesial temporal lobe ipsilateral to the surgical resection was correlated with increased post-surgical declines, thus supporting the "functional adequacy model" of hippocampal function. This model predicts that severity of decline depends on the function of the region resected and not on the ability of the 
contralateral region to support function after surgery ("functional reserve model") (Chelune 1995). These studies report positive predictive values of 56 to $100 \%$ (Richardson, et al. 2004) for fMRI to predict post-surgical change in memory neuropsychological scores. Interestingly, some more recent reports show that evaluating multiple regions of the language and memory networks, including those in the frontal and lateral temporal lobes, can improve this prediction (Binder, et al. 2008a, Binder, et al. 2010, Bonelli, et al. 2010, Everts, et al. 2010). Bonelli, et al. (Bonelli, et al. 2010) found that in their cohort the positive predictive value of memory fMRI activation asymmetry in the anterior temporal lobe was $20-35 \%$, but when fMRI language lateralization, calculated using multiple regions across the frontal and temporal lobes, and pre-operative neuropsychological scores are included, the positive predictive value rose to $70-100 \%$.

While fMRI activation of long range regions is informative, it is likely that probing the functional connectivity across language and/or memory networks may be a more direct measure of cognitive function or predictor of post-surgical function. However, the appropriate choices for regions and task paradigm (or none) remain unknown. Studies performed thus far have varied significantly in these study parameters, and so consistent results are few. One promising repeated finding is that the functional connectivity between the anterior cingulate and the left inferior frontal gyrus was found to be decreased in TLE compared to healthy controls during rest (Waites, et al. 2006) and during block-design performance of a word-generation task (Vlooswijk, et al. 2010). Similarly, the functional connectivity of the left hippocampus and other regions involved with memory was also decreased relative to controls (Addis, et al. 2007). Generally, these decreases in functional connectivity were associated with diminished cognitive performance as measured by the neuropsychological testing. In support of the functional adequacy model, higher fMRI connectivity of the ipsilateral hippocampus to the superior temporal gyrus was associated with greater decline of verbal memory performance after surgery (Wagner, et al. 2007).

While fMRI has great potential to identify noninvasive markers of language and memory cognition and post-surgical outcome, there are many possible sources of error and variability in fMRI methods. First, there can be much variability in task performance. Many patients have cognitive deficits which reduce their ability to cooperate, understand and remember the directions of the task. Including children in the patient population increases this variation even more. For many cognitive tasks, it is difficult to impossible to monitor externally how well the tasks are being performed. Also, fMRI analysis methods are not standard. Differences in statistical thresholds and regions of interest used to calculate laterality indices can also lead to uncertainty (Abbott, et al. 2010, Branco, et al. 2006, Sidtis 2007, Suarez, et al. 2008). Research focused on resolving these issues is required before it will be possible to utilize fMRI for assessing surgical risk of cognitive deficits.

\subsection{The default-mode network}

There are regions of the brain that have been regularly observed to reduce fMRI activity (deactivate) during performance of demanding cognitive tasks or goal directed behavior (Fox, et al. 2005). When studied in a wakeful resting state using positron emission tomography (PET), increases in cerebral metabolic rate for oxygen $\left(\mathrm{CMRO}_{2}\right)$ and cerebral blood flow (CBF) are detected in these regions over other regions of the brain (Raichle, et al. 2001). The data suggest the existence of a baseline activation level in these areas at rest above the mean level of the brain, which may reflect internal modes of cognition, such as 
mind wandering or daydreaming in this state. This collection of regions is commonly referred to as the "default-mode network" (DMN, network 2, Figure 1) and typically include the following regions (Buckner, et al. 2008): ventral medial prefrontal cortex, posterior cingulate/retrosplenial cortex, bilateral inferior parietal lobule, lateral temporal cortex, dorsal medial prefrontal cortex, and hippocampus.

In addition to being identified as a network of regions deactivated during goal-oriented cognitive tasks, this same network can reliably be identified by performing independent component analysis on resting state fMRI data (Damoiseaux, et al. 2006, De Luca, et al. 2006) and by seed region based functional connectivity analyses (Greicius, et al. 2003). Intersubject variability in the functional connectivity across the DMN is influenced by factors such as age (Grady, et al. 2010), cognitive load (i.e. eyes open vs. eyes closed) (Yan, et al. 2009), genetics (Glahn, et al. 2010), level of consciousness (Greicius, et al. 2008) and sleep (Horovitz, et al. 2008). It has been directly correlated in part to EEG delta and beta power (Hlinka, et al. 2010). However, the robustness of this network and its implications on baseline cognitive function and consciousness make it a frequent focus of investigations of neurological disease (Broyd, et al. 2009).

The relationship between DMN and epilepsy was first reported in activation studies of generalized spike-and-wave (GSW) bursts in patients with idiopathic generalized epilepsy (IGE) (Archer, et al. 2003, Gotman, et al. 2005, Hamandi, et al. 2006, Laufs, et al. 2006, SalekHaddadi, et al. 2003). In these studies, simultaneous measures of EEG and fMRI (Gotman, et al. 2004) were acquired in individual or groups of IGE patients with frequent GSW bursts on EEG. The EEG was used to determine the timing of any GSW bursts occurring during fMRI scanning. These times were then used to localize the regions of the brain in which the fMRI signal increased (activation) or decreased (deactivation) concurrently with the GSW bursts. While the results were somewhat variable across subjects, there was an overarching finding of positive activation located bilaterally in the thalamus and deactivation found in regions of the DMN. These findings suggest that the activation in the thalamus indicated this region's involvement in the generation or spread of generalized epileptic discharges. Furthermore, the authors propose that the combination of the activation of the thalamus with the deactivation of the DMN may lead to the lapse in responsiveness associated with absence seizures in IGE (Gotman, et al. 2005, Hamandi, et al. 2006). Conversely, there is evidence that the functional connectivity across the DMN assessed in IGE patients during time periods without GSW is not significantly different from healthy controls (Moeller, et al. 2011), indicating that this is primarily an ictal effect.

In order to verify the existence of a correlation between impaired consciousness and fMRI changes with GSW bursts, Berman et al. (Berman, et al. 2010) had a group of patients with typical childhood absence epilepsy perform a continuous performance task during the simultaneous EEG and fMRI acquisition. They used any interruption of task performance during the acquisition as an indicator of impaired consciousness. They then determined fMRI changes due to GSW bursts with interruption of the task and those without. During GSW bursts associated with interruption of the task, expected regions in the thalamus and cortex were activated and DMN regions were deactivated. However, when GSW bursts were not associated with task interruption, little fMRI change was detected. This suggests that the deactivation of the DMN and activation of the thalamus may be directly related to the impaired consciousness in absence seizures. On the other hand, in a case report of a study with similar methods, the expected fMRI activations and deactivations were detected 
in response to GSW bursts without task interruption (Moeller, et al. 2010b). The case study detected GSW bursts with an average duration of 4.2 seconds and with an fMRI temporal resolution of $2250 \mathrm{msec}$, whereas the group study included GSW bursts with an average duration of $6.2 \mathrm{sec}$ and an fMRI temporal resolution of $1550 \mathrm{msec}$. One may expect that the increased temporal resolution and longer periods of GSW of the group study may increase detectability of fMRI signal changes even without task interruption, if they were present. Further study is required to clarify this issue.

More recent studies have attempted to resolve timing differences between fMRI changes in the DMN and other regions in response to GSW bursts (Carney, et al. 2010, Moeller, et al. 2010a). Both studies showed fMRI deactivations in DMN generally occurring prior to the increased thalamic response. In several instances fMRI signal change in the DMN started prior to the event onset on EEG. Another study (Szaflarski, et al. 2010) found parietal (but not necessarily DMN) activation occurring prior to thalamic activation and also detected similar causal links using Granger causality measures of fMRI data (Deshpande, et al. 2009, Goebel, et al. 2003). Another causal methodology, dynamic causal modeling (Friston, et al. 2003), can estimate the influence of one system on another. This method was used to determine which of three models including the ventromedial prefrontal cortex, the thalamus and the precuneus best fit the fMRI time series data when assuming the GSW bursts on EEG as the input (Vaudano, et al. 2009). The results over the group of IGE patients indicated that the GSW bursts initially influenced the precuneus and then the other two regions. These may infer the role of the DMN in the initiation of absence seizures, contradicting previous theories of thalamic generation of GSW bursts. Overall, the current literature provides convincing evidence for the potential link between function of the DMN and absence seizures and GSW bursts, but the direct mechanism of this relationship remains unknown.

There is a smaller, but growing, body of work linking activity in the DMN with focal epilepsy. Using the simultaneous EEG and fMRI protocol, deactivation has been detected in DMN regions in response to interictal EEG spiking (Kobayashi, et al. 2006, Laufs, et al. 2007). Using the data-driven method, 2dTCA (Morgan \& Gore 2009, Morgan, et al. 2008), we have detected robust fMRI transient signal changes during resting, interictal periods in the DMN (Morgan, et al. 2007, Morgan, et al. 2010) in TLE patients.

Independent component analysis can assess the functional connectivity across the DMN in the interictal state, without temporally associating changes directly with interictal spiking. In unilateral TLE patients, this method has revealed decreased connectivity between the hippocampus (predominantly ipsilateral to the epilepsy) and the rest of the DMN as compared to healthy controls (Zhang, et al. 2010a). Similar finding were reported using a seed-based functional connectivity analysis in unilateral TLE patients performing a verbal memory task (Frings, et al. 2009). Linearly relating these changes in connectivity with epilepsy duration suggests that the mechanism of the disease is at least partly responsible for the dysfunction.

\subsection{Perception and attention networks}

While the language, memory and default-mode networks are the most commonly studied with fMRI in relation to epilepsy, this condition can have effects on other known networks across the brain that may possibly result in sensory or cognitive deficits. One such network is the auditory system in the bilateral superior temporal lobes including Heschl's gyrus, planum temporale and the temporal poles (part of network 3, Figure 1). Auditory function is 
integral in language (i.e. auditory sentence comprehension) and memory (i.e. verbal memory), which are known to be impaired in TLE (Fisher, et al. 2000, Helmstaedter, et al. 2003). However, auditory processing itself may also be impaired in these patients as suggested by increased errors, response times and latencies of electrical event-related potentials in response to auditory stimuli (more pronounced in IGE than TLE) in humans (Verleger, et al. 1997), and in auditory discrimination deficits in rat models of epilepsy (Neill, et al. 2005). These effects were explored in an fMRI functional connectivity study using independent component analysis that revealed decreased connectivity in auditory cortex networks in a group of bilateral mesial TLE patients as compared to healthy controls (Zhang, et al. 2009a). Furthermore, the decrease in connectivity across the auditory cortex was linearly correlated with increase in duration of disease (i.e. longer duration was associated with lower connectivity).

\begin{tabular}{|c|c|c|}
\hline Network & $\begin{array}{l}\text { Type of } \\
\text { epilepsy }\end{array}$ & $\begin{array}{l}\text { fMRI findings and uses } \\
\text { (activation and connectivity) }\end{array}$ \\
\hline Language & TLE & $\begin{array}{l}\text { Language fMRI tasks are effective in lateralizing and } \\
\text { potentially localizing dominant language regions; FC } \\
\text { across this network is decreased compared to controls }\end{array}$ \\
\hline Memory & TLE & $\begin{array}{l}\text { Memory fMRI paradigms have mixed results in } \\
\text { localizing memory functions; Memory and/or language } \\
\text { tasks activating mesial temporal structures and beyond } \\
\text { may be effective in predicting post-surgical memory } \\
\text { deficits; Most studies show increased activation is } \\
\text { associated with decreased post-surgical performance; } \\
\text { Decreased FC compared to controls; Increased FC from } \\
\text { ipsilateral hippocampus is correlated with decreased } \\
\text { post-surgical verbal memory performance }\end{array}$ \\
\hline Default-mode & IGE & $\begin{array}{l}\text { Deactivation in response to GSW bursts; May be related } \\
\text { to impaired consciousness; May be generator of GSW } \\
\text { bursts }\end{array}$ \\
\hline Default-mode & TLE & Deactivation in response to interictal spiking \\
\hline Auditory & TLE & $\begin{array}{l}\text { Decreases in FC across network positively compared to } \\
\text { controls; Decrease correlated with duration of disease }\end{array}$ \\
\hline Sensorimotor & TLE & $\begin{array}{l}\text { Decreases in FC at rest compared to controls; Decrease } \\
\text { correlated with duration of disease }\end{array}$ \\
\hline Visual & TLE & $\begin{array}{l}\text { Increases in FC in primary visual cortex, decreases in FC } \\
\text { across higher order visual regions such as MT+ } \\
\text { compared to controls at rest }\end{array}$ \\
\hline $\begin{array}{l}\text { Dorsal } \\
\text { Attention }\end{array}$ & TLE & $\begin{array}{l}\text { Decreases in FC at rest correlated with decreased scores } \\
\text { on the Trail Making Test }\end{array}$ \\
\hline
\end{tabular}

TLE $=$ temporal lobe epilepsy, IGE $=$ idiopathic generalized epilepsy, $\mathrm{FC}=$ fMRI functional connectivity, GSW bursts = generalized spike-and-wave bursts on EEG

Table 1. Summary of effects of epilepsy on brain networks determined using fMRI

In the same fMRI study (Zhang, et al. 2009a), the authors also compared connectivity across the sensorimotor cortex (part of network 3, Figure 1) in the pre and post-central gyri in the frontal lobes between bilateral TLE patients and controls. Like the auditory network, the 
sensorimotor network connectivity was diminished in the TLE group as duration of disease increased.

In the visual cortex (network 1, Figure 1), the functional connectivity findings in the same study were mixed (Zhang, et al. 2009a). The results showed increases in connectivity in TLE in primary visual cortex, coupled with decreases in higher order visual processing regions such as MT+ when compared to controls that decreased with duration of disease. These findings may be consistent with behavioral results that showed no differences between reaction time or accuracy responding to visual stimuli in IGE (Verleger, et al. 1997) or TLE (Grant, et al. 2008); but deficits in processing of visual stimuli detected by EEG studies of visual evoked potentials (Lucking, et al. 1970) and event-related potentials (Verleger, et al. 1997).

The dorsal attention network is another set of regions that is repeatedly and reliably identified in healthy subjects (part of network 4, Figure 1). This network is made up of the intraparietal sulcus and the junction of the pre-central and superior frontal sulcus (or frontal eye field) in each hemisphere (Fox, et al. 2006) and is involved in attention orienting in searching for a target among non-targets (Shulman, et al. 2003). This function can be assessed using a neuropsychological test called the Trail Making Test (Reitan \& Wolfson 1995) in which the subject connects numbers or letters in numerical or alphabetical order in a timed fashion. This and similar tests have been used in epilepsy to quantify the effects of different anti-epileptic drugs such as topiramate (negative effects) (Kockelmann, et al. 2003), zonisamide (negative effects) (Park, et al. 2008), lamotrigine (positive effects) and oxcarbazepine (positive effects) (Seo, et al. 2007) on cognition. Using the same ICA methods as in their previous work in perceptual networks above, Zhang et al. compared the resting functional connectivity in the dorsal attention network between patients with bilateral TLE and controls (Zhang, et al. 2009b). They found decreases across most of the network in TLE which correlated with decreased scores on the Trail Making Test. Interestingly, they also found an increase in the right superior frontal sulcus which also correlated with decreases in the Trail Making Test scores across patients.

\section{Unique epilepsy related networks}

In addition to the changes in known resting-state networks, epilepsy can alter connections between regions, thereby identifying networks unique to this condition. These networks may delineate seizure propagation, or impairment or compensatory mechanisms to structural and/or functional damage across the brain. The changes may be a result of the seizures or epilepsy, or may play a part in the underlying epileptogencity of a region. Furthermore, it may be more difficult to define these altered networks because they may be different even between patients with similar disease characteristics. Currently, most of the work in this area has focused on TLE and hippocampal networks.

\subsection{Intrahemispheric mesial temporal lobe networks}

It is known that the hippocampus and surrounding structures are most commonly the generators of seizures in mesial TLE. The networks that are comprised of these regions are potentially the most affected by the condition. Studies by Bettus et al. (Bettus, et al. 2010, Bettus, et al. 2009) have investigated intrahemispheric mesial temporal lobe networks in TLE at rest with the objective to determine whether resting-state functional connectivity can be 
used to determine the epileptogenic hemisphere. They identified five mesial temporal regions of interest in each hemisphere including the anterior and posterior hippocampus, amygdala, entorhinal cortex and the temporal pole. Intrahemispheric connectivity between these regions was compared to a group of healthy controls. Interestingly, there were decreases in connectivity between regions in both hemispheres in many subjects, but increases in connectivity compared to controls occurred primarily in the hemisphere contralateral to the seizures. This increase in resting functional connectivity, speculated to be a compensatory effect, was shown to have $63 \%$ sensitivity and $90 \%$ specificity in lateralizing the TLE.

\subsection{Interhemispheric mesial temporal lobe networks}

In addition to the intrahemispheric networks involving mesial temporal lobe structures in TLE, the network between the left and right hippocampus may very likely be one of the most susceptible to changes due to long term seizure propagation effects. However, the direct consequences of these effects on functional connectivity are not clear. In left TLE, the interhemispheric hippocampal network was found to be almost non-existent in a resting fMRI study of nine patients (Pereira, et al. 2010). In the same study, the connectivity between the hippocampi was stronger in a group of nine patients with right TLE than in left TLE, but both patient groups were significantly less than the strong interhemispheric hippocampal connectivity detected in the nine healthy controls. Another investigation quantified the interhemispheric connectivity in TLE during a spatial memory task which would utilize the network between these two regions (Frings, et al. 2008a). They found that hippocampal connectivity during the memory task significantly increased as age of onset of epilepsy increased; and that as disease duration increased hippocampal connectivity decreased. This suggests a negative effect of repeated seizures or hippocampal damage across this network during the task, which may be reflected in the poorer memory performance of TLE patients in general. However, the different behavioral states (resting vs. task) of the two studies and the lack of disease duration information in the resting study, make these difficult to interpret together.

In an attempt to reconcile these two studies, we recruited 15 TLE patients with left temporal ictal and interictal EEG, and 7 TLE patients with right temporal interictal and ictal EEG. We performed resting fMRI on a 3T MRI scanner using a 2 sec temporal sampling rate (compared to 2.0T MRI with a 2 sec sampling rate (Pereira, et al. 2010), and 1.5T MRI scanner with a 4 sec sampling rate (Frings, et al. 2008a)) and computed interhemispheric hippocampal connectivity using structurally defined hippocampal regions of interest similar to above. While no additional physiological noise corrections were performed in the two published studies, we linearly regressed motion and a global time course from the seed time courses before performing correlations. We compared connectivity to 12 healthy controls and found that there was no significant difference between the connectivity of controls and TLE patients, especially those patients with a shorter duration of disease (Figure 2, left). We also computed a linear correlation between connectivity and duration of disease. This revealed no significant correlation across the group of all TLE patients, but a significant decrease in connectivity as duration increased in the left TLE patients (correlation coefficient $=-0.531, \mathrm{p}=0.042$ ) (Figure 2, left).

Therefore, we were not able to duplicate the results of Pereira et al. to find decreased interhemispheric connectivity in the TLE patients, unless the patients in their study all had 
extensively long duration of disease (which is not stated). But, we were able to duplicate in left TLE at rest what Frings et al. showed during the memory task; that hippocampal connectivity decreased as duration of disease increased. However, it is clear that further study is required to fully understand this network and the effects of epilepsy on it. We believe that it is likely that the choice of hippocampal region of interest may have a significant effect on these results. To investigate this we identified functionally defined regions in the anterior left and right hippocampus that were about one-half the volume and completely within the structurally defined regions. The interhemispheric connectivity result from these regions was different from what was seen with anatomically defined regions (Figure 2, right). With the functionally-defined restricted regions, the connectivity across all TLE patients increased as duration of disease increased (correlation coefficient $=0.465, \mathrm{p}=$ 0.029). However, the connectivity across the group was not different from that in controls, possibly because the epilepsy was greater than 20 years in duration in several patients. This suggests that the anterior and posterior portions of the hippocampus are functionally distinct and that, perhaps, the effects of TLE occur initially in the anterior portion of the hippocampus.
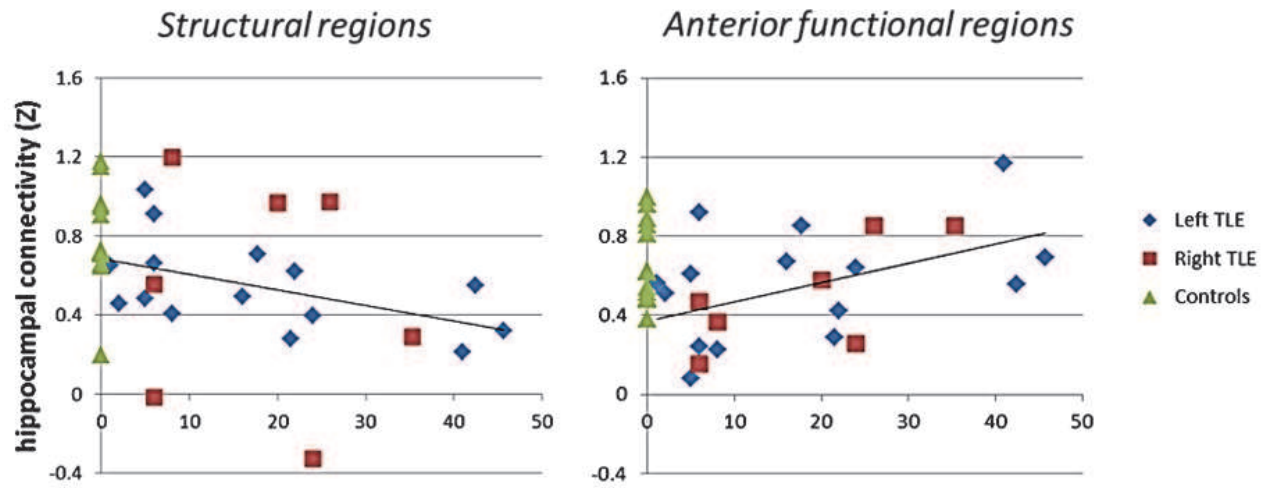

\section{duration of disease (yrs)}

Fig. 2. Interhemispheric hippocampal connectivity at rest in TLE patients and controls correlated with duration of disease. (Left) Measures calculated with structurally defined regions between the entire left and right hippocampus. Connectivity in Left TLE decreased as duration of disease increased $(p=0.042)$. (Right) Measures calculated with functionally defined regions in the anterior portion of the left and right hippocampus. Connectivity across all TLE patients increased as duration of disease increased $(p=0.029)$. Functionally defined regions are about one-half the volume of the structurally defined regions.

Hippocampal connectivity measures calculated using correlation coefficients as above, do not yield information regarding the direction of influence across the network. This can be determined using Granger causality analyses of fMRI data (Goebel, et al. 2003, Roebroeck, et al. 2005, Rogers, et al. 2010), but are most effective using faster temporal sampling (Deshpande, et al. 2010). Therefore, we performed a Granger causality analysis on fMRI data with a $500 \mathrm{~ms}$ temporal sampling rate using the functionally defined anterior hippocampal regions discussed above (Morgan, et al. 2011). We also determined the 
hippocampal connectivity measures using the faster sampled data. The results revealed that during the interictal state the interhemispheric hippocampal connectivity initially is disrupted and then linearly increases with the epilepsy duration longer than 10 years. This increase in connectivity appears to be due to the hippocampus contralateral to the epileptogenic focus exerting more influence over the ipsilateral hippocampus. These findings may have implications in understanding the functional development of epileptic networks in mTLE.
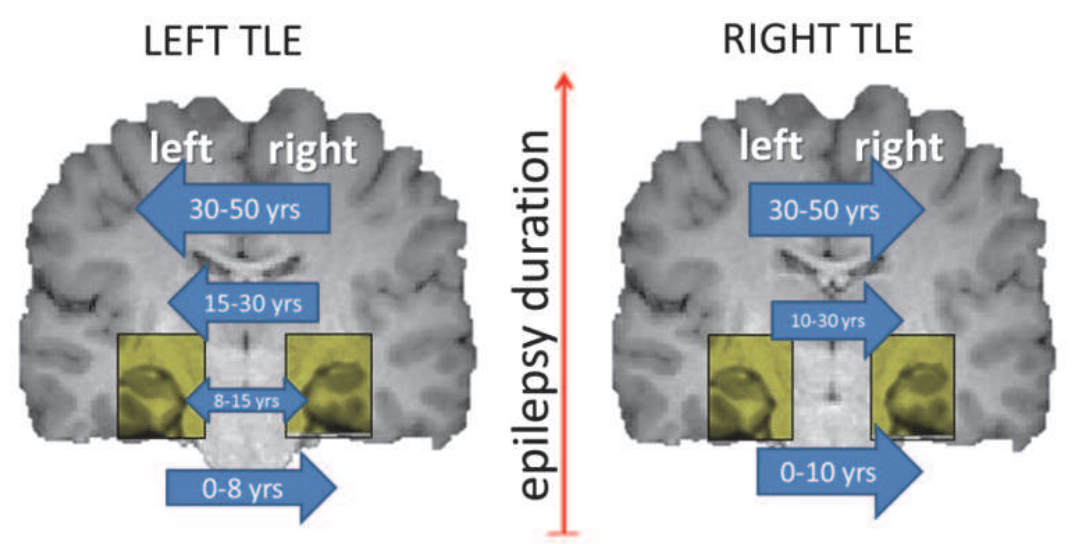

Fig. 3. Direction of hippocampal influence in TLE determined by Granger causality measures using high temporal resolution fMRI at rest. Direction and size of arrows represent direction and relative magnitude of influence between hippocampi at different periods of the epilepsy duration. At the longest duration, the hippocampus contralateral to the epileptogenic focus exerts more influence over the ipsilateral hippocampus.

\section{Other fMRI analysis methods applied to epilepsy network investigation}

\subsection{Clustering methods}

In addition to the ICA methods discussed, other types of data-driven techniques such as hierarchical clustering (Cordes, et al. 2002, Stanberry, et al. 2003) and fuzzy clustering (Baumgartner, et al. 2000, Dimitriadou, et al. 2004, Meyer-Baese, et al. 2004) use clustering of similar fMRI signal time courses to group and determine voxel time courses of interest. They are based on the assumption that BOLD stimuli will create a response in multiple voxels simultaneously. These techniques also are effective in fMRI data and have been applied to epilepsy data in animal models (Keogh, et al. 2005).

Temporal clustering analysis (TCA) is a method for determining times at which a significantly large number of voxels experience a similar response such as signal increase (Liu, et al. 2000, Lu, et al. 2006). This is done by creating a histogram of the number of voxels that individually reach their maximum (or contain some other shape of interest) at each time point of an imaging series. In other words, a plot of the number of voxels reaching a maximum or shape of interest (y-axis) versus time point in the series (x-axis) is created. Peaks in the histogram indicate the timing of many voxels experiencing the shape of interest indicating brain activity in response to whatever stimulus was present. The basis of this 
technique is that the probability of maximal signal intensity of each voxel is equal for all times unless the response to some stimulus occurs. Therefore, if no stimuli were present, the histogram would be relatively flat. Liu et al. first developed this method to identify time of maximal activation after eating (Liu, et al. 2000). The advantage of this technique is that it can detect specific time course characteristics of interest.

Any of the data-driven approaches above could be used to search for the BOLD responses of epileptic discharges in fMRI time series. When using ICA type methods, the results will include all components of the signal, regardless of amplitude or shape. Further investigations would be required to determine which of these components contain the signals of interest (De Martino, et al. 2007). In the case of interictal activity, the signal of interest is based on the hemodynamic response of the electrical spike activity. The TCA techniques can be "tuned" to this signal of interest. However, for success of any clustering algorithms we must assume that these discharges give rise to significant BOLD signal changes. This is supported by the work of Krakow et al. (Krakow, et al. 2001) in which they found, using EEG-triggered fMRI, that $34.9 \%$ of interictal spikes in a subject were associated with significant focal fMRI activation (signal intensity increases) consistent with results from several spikes averaged together. In fact, TCA has been used relatively successfully to localize epileptic discharges in animal models (Makiranta, et al. 2005) and in humans (Morgan, et al. 2004).

However, the original TCA methods map all signal changes of the desired shape into one histogram and therefore, they are highly sensitive to motion, physiological noise and other sources of signal change that may have the signal shape of interest (Hamandi, et al. 2005). Therefore, we have developed of a two-dimensional TCA technique (2dTCA) which creates separate histograms for groups of voxels with a similar timing of transient signal increases (epileptic spike). Using the 2dTCA technique we have developed, multiple histograms are created as columns on a two-dimensional grid. Thereby, groups of voxels with different timing patterns will be grouped in different "components". We evaluated the performance of 2dTCA in simulated functional MRI datasets (Morgan, et al. 2008). Comparisons were made with TCA and a freely-distributed ICA algorithm. The results suggest that the increased sensitivity of 2dTCA over TCA in detecting this particular signal of interest is comparable to detection with ICA, but with fewer other signals detected. We further validated it in healthy volunteers with controlled stimulus timing (Morgan \& Gore 2009). Finally, we were able to implement this method to detect regions of activation in the left mesial temporal lobe, bilateral insula and default-mode network in a group of left TLE patients (Morgan, et al. 2007, Morgan, et al. 2010). Using the region of activation in the mesial temporal lobe as the seed, we were able to calculate functional connectivity to the rest of the brain to detect changes from healthy controls (Morgan, et al. 2010). This revealed a network including the thalamus, brainstem, frontal and parietal regions consistent with the "network inhibition hypothesis" (Norden \& Blumenfeld 2002, Yu \& Blumenfeld 2009). This theory proposes that complex partial seizures originating in the mesial temporal lobes may propagate to the medial thalamus and upper brain stem which inhibits function of the frontal and parietal cortices causing loss of consciousness.

\subsection{Graph theory applied to fMRI network analysis}

One method to model the complex structural and functional networks of the brain is by using graph theoretical analysis (He \& Evans 2010). This method is described as a powerful 
mathematical framework for characterizing the organization of the complicated networks. He et al. (He \& Evans 2010) describe how structural and functional brain networks can be modeled using various MRI and EEG techniques. This theory assumes that the brain consists of nodes (voxels or regions) and edges (the connections between the nodes). Characteristics about the nodes and edges are determined such as the presence of hubs, or highly connected nodes. Other characteristics include shortest path lengths and clustering parameters. Liao et al. (Liao, et al. 2010) used graph theory to compare fMRI data from TLE patients and controls by identifying 90 cortical and subcortical nodes across the brain. They found that the TLE patients had increased connectivity within the mesial temporal lobes and decreased connectivity in the frontal and parietal lobes, consistent with several other methodologies discussed in this chapter. They also found decreases in the number of connections in the DMN in the patients. Overall, this is a potentially powerful, quantitative method for assessing small-world properties and network robustness in the brain.

\subsection{Regional homogeneity (ReHo) analysis}

The regional homogeneity (ReHo) analysis is an fMRI analysis method to probe the most local connections in a given region of the brain first developed by Zang et al. (Zang, et al. 2004). The ReHo is measured by determining the local coherence of the fMRI time series of a given voxel to all of its directly neighboring voxels using Kendall's coefficient of concordance (Kendall \& Gibbons 1990). The assumption is that increases in the ReHo value will reflect changes in neuronal activity, however the direct link is not known. This method has been used in numerous studies including those in autism (Shukla, et al. 2010), depression (Liu, et al. 2010) and intelligence in healthy controls (Wang, et al. 2011). In a group of non-lesional children with TLE, increased ReHo was found in the posterior cingulate and the right medial temporal lobe. Decreased ReHo was detected in right frontal gyrus and the cerebellum. There were also differences between those patients with abnormal EEG and those without. The significance of these ReHo changes are not known, but the authors suggest that this increased local synchronization aids in the spread of epileptiform activity (Mankinen, et al. 2011).

\subsection{Amplitude of low frequency fluctuation (ALFF) analysis}

It has been determined that the spontaneous fluctuations measured using functional connectivity analyses are in the low frequency range $(0.01-0.08 \mathrm{~Hz})$ (Cordes, et al. 2001). Therefore, it is possible that the power of these low frequency fluctuations can be informative regarding the characteristics of the underlying neuronal activity generating these signals (Duff, et al. 2008). From this idea, Zang et al. developed the "amplitude of low frequency fluctuation" (ALFF) analysis. The general method is to do a voxel-wise calculation of the low-frequency power, and to statistically compare this power across the brain or other series. This method has been used to compare visual states in healthy controls (Yang, et al. 2007) and to study schizophrenia (Hoptman, et al. 2010, Huang, et al. 2010) and attention deficit disorder (Zang, et al. 2007). The approach was used to compare a group of unilateral TLE patients to healthy controls (Zhang, et al. 2010b). Similar to other methods of connectivity, increases in the TLE patients were detected in the bilateral hippocampi, amygdala, temporal pole, midbrain and lateral temporal and parietal regions. Decreases in ALFF in TLE patients were detected in the DMN. The patients also showed an asymmetry in their ALFF measures in the mesial temporal lobes and thalamus, possibly indicating the epileptogenic region. 


\section{Conclusions and future directions}

In this chapter we have discussed the numerous ways in which epilepsy can affect the functional networks of the brain and the various fMRI methods used to determine this. We also explained how these changes may be related to behavioral, cognitive or disease characteristics. In parallel to the functional connectivity work being pursued, a large effort has been devoted to examining the same issues in relation to MRI measured structural connectivity (Focke, et al. 2008). The comparison between functional and structural connectivity in epilepsy may provide answers that neither method can individually (Voets, et al. 2009). We believe that large scale neuroimaging studies that incorporate both structural and functional imaging with genetic, physiological and neuropsychological testing, like those for controls (The Human Connectome Project, www.humanconnectome.org) and Alzheimer's Disease (Alzheimer's Disease Neuroimaging Initiative (ADNI), University of California, San Francisco, USA) already underway, may provide the greatest potential in uncovering the mechanisms and effects of network alterations in the brain in epilepsy.

\section{Abbreviations}

ADNI - Alzheimer's Disease Neuroimaging Initiative

ALFF - amplitude of low frequency fluctuations

BOLD - blood oxygen level dependent

CBF - cerebral blood flow

$\mathrm{CMRO} 2$ - cerebral metabolic rate for oxygen

DMN - default mode network

EEG - electroencephalography

fMRI - functional Magnetic Resonance Imaging

GSW - generalize spike-and-wave

IAT - Intracarotid Amobarbital Test

ICA - independent component analysis

IGE - idiopathic generalized epilepsy

MEG - magnetoencephalography

PET - positron emission tomography

ReHo - regional homogeneity

SPECT - single photon emission tomography

TCA, 2dTCA - temporal clustering analysis, two-dimensional temporal clustering analysis TLE - temporal lobe epilepsy

\section{Acknowledgements}

This work was supported in part by NIH R01 NS055822.

\section{References}

Abbott, D.F., Waites, A.B., Lillywhite, L.M. \& Jackson, G.D. (2010) fMRI assessment of language lateralization: An objective approach. Neuroimage 50:1446-1455. 
Abou-Khalil, B. (2007) An update on determination of language dominance in screening for epilepsy surgery: the Wada test and newer noninvasive alternatives. Epilepsia 48:442-455.

Addis, D.R., Moscovitch, M. \& McAndrews, M.P. (2007) Consequences of hippocampal damage across the autobiographical memory network in left temporal lobe epilepsy. Brain 130:2327-2342.

Archer, J.S., Abbott, D.F., Waites, A.B. \& Jackson, G.D. (2003) fMRI "deactivation" of the posterior cingulate during generalized spike and wave. Neuroimage 20:1915-1922.

Arora, J., Pugh, K., Westerveld, M., Spencer, S., Spencer, D.D. \& Constable, R.T. (2009) Language lateralization in epilepsy patients: fMRI validated with the Wada procedure. Epilepsia 50:2225-2241.

Baumgartner, R., Ryner, L., Richter, W., Summers, R., Jarmasz, M. \& Somorjai, R. (2000) Comparison of two exploratory data analysis methods for fMRI: fuzzy clustering vs. principal component analysis. Magn Reson Imaging 18:89-94.

Baxendale, S., Thompson, P.J. \& Duncan, J.S. (2008) The role of the Wada test in the surgical treatment of temporal lobe epilepsy: An international survey. Epilepsia 49:715-720.

Berman, R., Negishi, M., Vestal, M., Spann, M., Chung, M.H., Bai, X.X., Purcaro, M., Motelow, J.E., Danielson, N., Dix-Cooper, L., Enev, M., Novotny, E.J., Constable, R.T. \& Blumenfeld, H. (2010) Simultaneous EEG, fMRI, and behavior in typical childhood absence seizures. Epilepsia 51:2011-2022.

Bettus, G., Bartolomei, F., Confort-Gouny, S., Guedj, E., Chauvel, P., Cozzone, P.J., Ranjeva, J.P. \& Guye, M. (2010) Role of resting state functional connectivity MRI in presurgical investigation of mesial temporal lobe epilepsy. J. Neurol. Neurosurg. Psychiatry 81:1147-1154.

Bettus, G., Guedj, E., Joyeux, F., Confort-Gouny, S., Soulier, E., Laguitton, V., Cozzone, P.J., Chauvel, P., Ranjeva, J.P., Bartolomei, F. \& Guye, M. (2009) Decreased basal fMRI functional connectivity in epileptogenic networks and contralateral compensatory mechanisms. Human brain mapping 30:1580-1591.

Binder, J.R., Sabsevitz, D.S., Swanson, S.J., Hammeke, T.A., Raghavan, M. \& Mueller, W.M. (2008a) Use of preoperative functional MRI to predict verbal memory decline after temporal lobe epilepsy surgery. Epilepsia 49:1377-1394.

Binder, J.R., Swanson, S.J., Hammeke, T.A. \& Sabsevitz, D.S. (2008b) A comparison of five fMRI protocols for mapping speech comprehension systems. Epilepsia 49:1980-1997.

Binder, J.R., Swanson, S.J., Sabsevitz, D.S., Hammeke, T.A., Raghavan, M. \& Mueller, W.M. (2010) A comparison of two fMRI methods for predicting verbal memory decline after left temporal lobectomy: Language lateralization versus hippocampal activation asymmetry. Epilepsia 51:618-626.

Biswal, B., Yetkin, F.Z., Haughton, V.M. \& Hyde, J.S. (1995) Functional connectivity in the motor cortex of resting human brain using echo-planar MRI. Magn Reson Med 34:537-541.

Blumenfeld, H., McNally, K.A., Vanderhill, S.D., Paige, A.L., Chung, R., Davis, K., Norden, A.D., Stokking, R., Studholme, C., Novotny, E.J., Jr., Zubal, I.G. \& Spencer, S.S. (2004a) Positive and negative network correlations in temporal lobe epilepsy. Cereb Cortex 14:892-902.

Blumenfeld, H., Rivera, M., McNally, K.A., Davis, K., Spencer, D.D. \& Spencer, S.S. (2004b) Ictal neocortical slowing in temporal lobe epilepsy. Neurology 63:1015-1021. 
Blumenfeld, H., Varghese, G.I., Purcaro, M.J., Motelow, J.E., Enev, M., McNally, K.A., Levin, A.R., Hirsch, L.J., Tikofsky, R., Zubal, I.G., Paige, A.L. \& Spencer, S.S. (2009) Cortical and subcortical networks in human secondarily generalized tonic-clonic seizures. Brain 132:999-1012.

Bonelli, S.B., Powell, R.H.W., Yogarajah, M., Samson, R.S., Symms, M.R., Thompson, P.J., Koepp, M.J. \& Duncan, J.S. (2010) Imaging memory in temporal lobe epilepsy: predicting the effects of temporal lobe resection. Brain 133:1186-1199.

Bookheimer, S. (2007) Pre-surgical language mapping with functional magnetic resonance imaging. Neuropsychol. Rev. 17:145-155.

Branco, D.M., Suarez, R.O., Whalen, S., O'Shea, J.P., Nelson, A.P., da Costa, J.C. \& Golby, A.J. (2006) Functional MRI of memory in the hippocampus: Laterality indices may be more meaningful if calculated from whole voxel distributions. Neuroimage 32:592-602.

Broyd, S.J., Demanuele, C., Debener, S., Helps, S.K., James, C.J. \& Sonuga-Barke, E.J.S. (2009) Default-mode brain dysfunction in mental disorders: A systematic review. Neurosci. Biobehav. Rev. 33:279-296.

Buckner, R.L., Andrews-Hanna, J.R. \& Schacter, D.L. (2008) The brain's default network: anatomy, function, and relevance to disease. Ann N Y Acad Sci 1124:1-38.

Calhoun, V.D., Adali, T., Hansen, L.K., Larsen, J. \& Pekar, J.J. (2003) ICA of functional MRI data: an overview. 4th International Symposium on ICA and BLind Separation, Nara, Japan.

Carney, P.W., Masterton, R.A.J., Harvey, A.S., Scheffer, I.E., Berkovic, S.F. \& Jackson, G.D. (2010) The core network in absence epilepsy Differences in cortical and thalamic BOLD response. Neurology 75:904-911.

Cascino, G.D. \& Jack, C.R. (1996) Neuroimagingin Epilepsy: Principals and Practice. Butterworth-Heinemann, Boston, MA.

Chelune, G.J. (1995) Hippocampal adequacy versus functional reserve: predicting memory functions following temporal lobectomy. Arch Clin Neuropsychol 10:413-432.

Cordes, D., Haughton, V., Carew, J.D., Arfanakis, K. \& Maravilla, K. (2002) Hierarchical clustering to measure connectivity in fMRI resting-state data. Magnetic Resonance Imaging 20:305-317.

Cordes, D., Haughton, V.M., Arfanakis, K., Carew, J.D., Turski, P.A., Moritz, C.H., Quigley, M.A. \& Meyerand, M.E. (2001) Frequencies contributing to functional connectivity in the cerebral cortex in "resting-state" data. Ajnr 22:1326-1333.

Damoiseaux, J.S., Rombouts, S.A.R.B., Barkhof, F., Scheltens, P., Stam, C.J., Smith, S.M. \& Beckmann, C.F. (2006) Consistent resting-state networks across healthy subjects. Proceedings of the National Academy of Sciences of the United States of America 103:13848-13853.

De Luca, M., Beckmann, C.F., De Stefano, N., Matthews, P.M. \& Smith, S.M. (2006) fMRI resting state networks define distinct modes of long-distance interactions in the human brain. Neuroimage 29:1359-1367.

De Martino, F., Gentile, F., Esposito, F., Balsi, M., Di Salle, F., Goebel, R. \& Formisano, E. (2007) Classification of fMRI independent components using IC-fingerprints and support vector machine classifiers. Neuroimage 34:177-194.

de Pasquale, F., Della Penna, S., Snyder, A.Z., Lewis, C., Mantini, D., Marzetti, L., Belardinelli, P., Ciancetta, L., Pizzella, V., Romani, G.L. \& Corbetta, M. (2010) 
Temporal dynamics of spontaneous MEG activity in brain networks. Proceedings of the National Academy of Sciences of the United States of America 107:6040-6045.

Deblaere, K., Backes, W.H., Hofman, P., Vandemaele, P., Boon, P.A., Vonck, K., Boon, P., Troost, J., Vermeulen, J., Wilmink, J., Achten, E. \& Aldenkamp, A. (2002) Developing a comprehensive presurgical functional MRI protocol for patients with intractable temporal lobe epilepsy: a pilot study. Neuroradiology 44:667-673.

Deblaere, K., Backes, W.H., Tieleman, A., Vandemaele, P., Defreyne, L., Vonck, K., Hofman, P., Boon, P., Vermeulen, J., Wilmink, J., Aldenkamp, A., Boon, P., Vingerhoets, G. \& Achten, E. (2005) Lateralized anterior mesiotemporal lobe activation: Semirandom functional MR imaging encoding paradigm in patients with temporal lobe epilepsy-initial experience. Radiology 236:996-1003.

Deshpande, G., LaConte, S., James, G.A., Peltier, S. \& Hu, X.P. (2009) Multivariate Granger Causality Analysis of fMRI Data. Human brain mapping 30:1361-1373.

Deshpande, G., Sathian, K. \& Hu, X.P. (2010) Effect of hemodynamic variability on Granger causality analysis of fMRI. Neuroimage 52:884-896.

Dimitriadou, E., Barth, M., Windischberger, C., Hornik, K. \& Moser, E. (2004) A quantitative comparison of functional MRI cluster analysis. Artif. Intell. Med. 31:57-71.

Duff, E.P., Johnston, L.A., Xiong, J.H., Fox, P.T., Mareels, I. \& Egan, G.F. (2008) The power of spectral density analysis for mapping endogenous BOLD signal fluctuations. Human brain mapping 29:778-790.

Englot, D.J., Mishra, A.M., Mansuripur, P.K., Herman, P., Hyder, F. \& Blumenfeld, H. (2008) Remote effects of focal hippocampal seizures on the rat neocortex. J Neurosci 28:9066-9081.

Everts, R., Harvey, A.S., Lillywhite, L., Wrennall, J., Abbott, D.F., Gonzalez, L., Kean, M., Jackson, G.D. \& Anderson, V. (2010) Language lateralization correlates with verbal memory performance in children with focal epilepsy. Epilepsia 51:627-638.

Fisher, R.S., Vickrey, B.G., Gibson, P., Hermann, B., Penovich, P., Scherer, A. \& Walker, S. (2000) The impact of epilepsy from the patient's perspective I. Descriptions and subjective perceptions. Epilepsy research 41:39-51.

Focke, N.K., Yogarajah, M., Bonelli, S.B., Bartlett, P.A., Symms, M.R. \& Duncan, J.S. (2008) Voxel-based diffusion tensor imaging in patients with mesial temporal lobe epilepsy and hippocampal sclerosis. Neuroimage 40:728-737.

Fox, M.D., Corbetta, M., Snyder, A.Z., Vincent, J.L. \& Raichle, M.E. (2006) Spontaneous neuronal activity distinguishes human dorsal and ventral attention systems. Proceedings of the National Academy of Sciences of the United States of America 103:10046-10051.

Fox, M.D., Snyder, A.Z., Vincent, J.L., Corbetta, M., Van Essen, D.C. \& Raichle, M.E. (2005) The human brain is intrinsically organized into dynamic, anticorrelated functional networks. Proceedings of the National Academy of Sciences of the United States of America 102:9673-9678.

Fransson, P., Skiold, B., Horsch, S., Nordell, A., Blennow, M., Lagercrantz, H. \& Aden, U. (2007) Resting-state networks in the infant brain. Proceedings of the National Academy of Sciences of the United States of America 104:15531-15536.

Frings, L., Schulze-Bonhage, A., Spreer, J. \& Wagner, K. (2008a) Reduced interhemispheric hippocampal BOLD signal coupling related to early epilepsy onset. Seizure 18:153157. 
Frings, L., Schulze-Bonhage, A., Spreer, J. \& Wagner, K. (2009) Remote effects of hippocampal damage on default network connectivity in the human brain. Journal of neurology 256:2021-2029.

Frings, L., Wagner, K., Halsband, U., Schwarzwald, R., Zentner, J. \& Schulze-Bonhage, A. (2008b) Lateralization of hippocampal activation differs between left and right temporal lobe epilepsy patients and correlates with postsurgical verbal learning decrement. Epilepsy research 78:161-170.

Friston, K.J., Harrison, L. \& Penny, W. (2003) Dynamic causal modelling. Neuroimage 19:1273-1302.

Gaillard, W.D., Balsamo, L., Xu, B., Grandin, C.B., Braniecki, S.H., Papero, P.H., Weinstein, S., Conry, J., Pearl, P.L., Sachs, B., Sato, S., Jabbari, B., Vezina, L.G., Frattali, C. \& Theodore, W.H. (2002) Language dominance in partial epilepsy patients identified with an fMRI reading task. Neurology 59:256-265.

Glahn, D.C., Winkler, A.M., Kochunov, P., Almasy, L., Duggirala, R., Carless, M.A., Curran, J.C., Olvera, R.L., Laird, A.R., Smith, S.M., Beckmann, C.F., Fox, P.T. \& Blangero, J. (2010) Genetic control over the resting brain. Proceedings of the National Academy of Sciences of the United States of America 107:1223-1228.

Goebel, R., Roebroeck, A., Kim, D.S. \& Formisano, E. (2003) Investigating directed cortical interactions in time-resolved fMRI data using vector autoregressive modeling and Granger causality mapping. Magnetic Resonance Imaging 21:1251-1261.

Golby, A.J., Poldrack, R.A., Brewer, J.B., Spencer, D., Desmond, J.E., Aron, A.P. \& Gabrieli, J.D.E. (2001) Material-specific lateralization in the medial temporal lobe and prefrontal cortex during memory encoding. Brain 124:1841-1854.

Golby, A.J., Poldrack, R.A., Illes, J., Chen, D., Desmond, J.E. \& Gabrieli, J.D.E. (2002) Memory lateralization in medial temporal lobe epilepsy assessed by functional MRI. Epilepsia 43:855-863.

Gotman, J., Benar, C.G. \& Dubeau, F. (2004) Combining EEG and FMRI in epilepsy: methodological challenges and clinical results. J. Clin. Neurophysiol. 21:229-240.

Gotman, J., Grova, C., Bagshaw, A., Kobayashi, E., Aghakhani, Y. \& Dubeau, F. (2005) Generalized epileptic discharges show thalamocortical activation and suspension of the default state of the brain. Proceedings of the National Academy of Sciences of the United States of America 102:15236-15240.

Grady, C.L., Protzner, A.B., Kovacevic, N., Strother, S.C., Afshin-Pour, B., Wojtowicz, M., Anderson, J.A.E., Churchill, N. \& McIntosh, A.R. (2010) A Multivariate Analysis of Age-Related Differences in Default Mode and Task-Positive Networks across Multiple Cognitive Domains. Cereb Cortex 20:1432-1447.

Grant, A.C., Donnelly, K.M., Chubb, C., Barr, W.B., Kuzniecky, R. \& Devinsky, O. (2008) Temporal lobe epilepsy does not impair visual perception. Epilepsia 49:710-713.

Greicius, M.D., Kiviniemi, V., Tervonen, O., Vainionpaa, V., Alahuhta, S., Reiss, A.L. \& Menon, V. (2008) Persistent default-mode network connectivity during light sedation. Human brain mapping 29:839-847.

Greicius, M.D., Krasnow, B., Reiss, A.L. \& Menon, V. (2003) Functional connectivity in the resting brain: a network analysis of the default mode hypothesis. Proceedings of the National Academy of Sciences of the United States of America 100:253-258. 
Guye, M., Regis, J., Tamura, M., Wendling, F., McGonigal, A., Chauvel, P. \& Bartolomei, F. (2006) The role of corticothalamic coupling in human temporal lobe epilepsy. Brain 129:1917-1928.

Hamandi, K., Salek-Haddadi, A., Laufs, H., Liston, A., Friston, K., Fish, D.R., Duncan, J.S. \& Lemieux, L. (2006) EEG-fMRI of idiopathic and secondarily generalized epilepsies. Neuroimage 31:1700-1710.

Hamandi, K., Salek Haddadi, A., Liston, A., Laufs, H., Fish, D.R. \& Lemieux, L. (2005) fMRI temporal clustering analysis in patients with frequent interictal epileptiform discharges: comparison with EEG-driven analysis. Neuroimage 26:309-316.

He, Y. \& Evans, A. (2010) Graph theoretical modeling of brain connectivity. Current opinion in neurology 23:341-350.

Helmstaedter, C., Kurthen, M., Lux, S., Reuber, M. \& Elger, C.E. (2003) Chronic epilepsy and cognition: A longitudinal study in temporal lobe epilepsy. Ann Neurol 54:425-432.

Hlinka, J., Alexakis, C., Diukova, A., Liddle, P.F. \& Auer, D.P. (2010) Slow EEG pattern predicts reduced intrinsic functional connectivity in the default mode network: An inter-subject analysis. Neuroimage 53:239-246.

Hoptman, M.J., Zuo, X.N., Butler, P.D., Javitt, D.C., D'Angelo, D., Mauro, C.J. \& Milham, M.P. (2010) Amplitude of low-frequency oscillations in schizophrenia: A resting state fMRI study. Schizophr. Res. 117:13-20.

Horovitz, S.G., Fukunaga, M., de Zwart, J.A., van Gelderen, P., Fulton, S.C., Balkin, T.J. \& Duyn, J.H. (2008) Low frequency BOLD fluctuations during resting wakefulness and light sleep: A simultaneous EEG-fMRI study. Human brain mapping 29:671-682.

Huang, X.Q., Lui, S., Deng, W., Chan, R.C.K., Wu, Q.Z., Jiang, L.J., Zhang, J.R., Jia, Z.Y., Li, F., Li, X.L., Chen, L., Li, T. \& Gong, Q.Y. (2010) Localization of cerebral functional deficits in treatment-naive, first-episode schizophrenia using resting-state fMRI. Neuroimage 49:2901-2906.

Jokeit, H., Okujava, M. \& Woermann, F.G. (2001) Memory fMRI lateralizes temporal lobe epilepsy. Neurology 57:1786-1793.

Kendall, M. \& Gibbons, J.D. (1990) Rank Correlation Methods. Edward Arnold, New York.

Keogh, B.P., Cordes, D., Stanberry, L., Figler, B.D., Robbins, C.A., Tempel, B.L., Green, C.G., Emmi, A., Maravilla, K.M. \& Schwartzkroin, P.A. (2005) BOLD-fMRI of PTZinduced seizures in rats. Epilepsy research 66:75-90.

Kilpatrick, C., Murrie, V., Cook, M., Andrewes, D., Desmond, P. \& Hopper, J. (1997) Degree of left hippocampal atrophy correlates with severity of neuropsychological deficits. Seizure 6:213-218.

Kobayashi, E., Bagshaw, A.P., Grova, C., Dubeau, F. \& Gotman, J. (2006) Negative BOLD responses to epileptic spikes. Human brain mapping 27:488-497.

Kockelmann, E., Elger, C.E. \& Hehnstaedter, C. (2003) Significant improvement in frontal lobe associated neuropsychological functions after withdrawal of Topiramate in epilepsy patients. Epilepsy research 54:171-178.

Krakow, K., Messina, D., Lemieux, L., Duncan, J.S. \& Fish, D.R. (2001) Functional MRI activation of individual interictal epileptiform spikes. Neuroimage 13:502-505.

Langfitt, J.T., Westerveld, M., Hamberger, M.J., Walczak, T.S., Cicchetti, D.V., Berg, A.T., Vickrey, B.G., Barr, W.B., Sperling, M.R., Masur, D. \& Spencer, S.S. (2007) Worsening of quality of life after epilepsy surgery: effect of seizures and memory decline. Neurology 68:1988-1994. 
Langfitt, J.T. \& Wiebe, S. (2008) Early surgical treatment for epilepsy. Current opinion in neurology 21:179-183.

Laufs, H., Hamandi, K., Salek-Haddadi, A., Kleinschmidt, A.K., Duncan, J.S. \& Lemieux, L. (2007) Temporal lobe interictal epileptic discharges affect cerebral activity in "Default mode" brain regions. Human brain mapping 28:1023-1032.

Laufs, H., Lengler, U., Hamandi, K., Kleinschmidt, A. \& Krakow, K. (2006) Linking generalized spike-and-wave discharges and resting state brain activity by using EEG/fMRI in a patient with absence seizures. Epilepsia 47:444-448.

Liao, W., Zhang, Z.Q., Pan, Z.Y., Mantini, D., Ding, J.R., Duan, X.J., Luo, C., Lu, G.M. \& Chen, H.F. (2010) Altered Functional Connectivity and Small-World in Mesial Temporal Lobe Epilepsy. Plos One 5:e8525.

Liu, Y., Gao, J.H., Liu, H.L. \& Fox, P.T. (2000) The temporal response of the brain after eating revealed by functional MRI. Nature 405:1058-1062.

Liu, Z.F., Xu, C., Xu, Y., Wang, Y.F., Zhao, B., Lv, Y.T., Cao, X.H., Zhang, K.R. \& Du, C.X. (2010) Decreased regional homogeneity in insula and cerebellum: A resting-state fMRI study in patients with major depression and subjects at high risk for major depression. Psychiatry Res. Neuroimaging 182:211-215.

Loddenkemper, T., Morris, H.H. \& Moddel, G. (2008) Complications during the Wada test. Epilepsy Behav 13:551-553.

Logothetis, N.K., Pauls, J., Augath, M., Trinath, T. \& Oeltermann, A. (2001) Neurophysiological investigation of the basis of the fMRI signal. Nature 412:150157.

Lu, N., Shan, B.C., Li, K., Yan, B., Wang, W. \& Li, K.C. (2006) Improved temporal clustering analysis method for detecting multiple response peaks in fMRI. Journal of Magnetic Resonance Imaging 23:285-290.

Lucking, C.H., Creutzfe.Od \& Heineman.U. (1970) Visual Evoked Potenials of Patients With Epilepsy and of a Control Group. Electroencephalogr. Clin. Neurophysiol. 29:557-\&.

Makiranta, M., Ruohonen, J., Suominen, K., Niinimaki, J., Sonkajarvi, E., Kiviniemi, V., Seppanen, T., Alahuhta, S., Jantti, V. \& Tervonen, O. (2005) BOLD signal increase preceeds EEG spike activity - a dynamic penicillin induced focal epilepsy in deep anesthesia. Neuroimage 27:715-724.

Mankinen, K., Long, X.-Y., Paakki, J.-J., Harila, M., Rytky, S., Tervonen, O., Nikkinen, J., Starck, T., Remes, J., Rantala, H., Zang, Y.-F. \& Kiviniemi, V. (2011) Alterations in regional homogeneity of baseline brain activity in pediatric temporal lobe epilepsy. Brain Res. 1373:221-229.

Mantini, D., Perrucci, M.G., Del Gratta, C., Romani, G.L. \& Corbetta, M. (2007) Electrophysiological signatures of resting state networks in the human brain. Proceedings of the National Academy of Sciences of the United States of America 104:13170-13175.

Medina, L.S., Aguirre, E., Bernal, B. \& Altman, N.R. (2004) Functional MR imaging versus Wada test for evaluation of language lateralization: Cost analysis. Radiology 230:4954.

Meyer-Baese, A., Wismueller, A. \& Lange, O. (2004) Comparison of two exploratory data analysis methods for fMRI: unsupervised clustering versus independent component analysis. IEEE Trans Inf Technol Biomed 8:387-398. 
Moeller, F., LeVan, P., Muhle, H., Stephani, U., Dubeau, F., Siniatchkin, M. \& Gotman, J. (2010a) Absence seizures: Individual patterns revealed by EEG-fMRI. Epilepsia 51:2000-2010.

Moeller, F., Maneshi, M., Pittau, F., Gholipour, T., Bellec, P., Dubeau, F., Grova, C. \& Gotman, J. (2011) Functional connectivity in patients with idiopathic generalized epilepsy. Epilepsia 52:515-522.

Moeller, F., Muhle, H., Wiegand, G., Wolff, S., Stephani, U. \& Siniatchkin, M. (2010b) EEGfMRI study of generalized spike and wave discharges without transitory cognitive impairment. Epilepsy Behav. 18:313-316.

Morgan, V.L. \& Gore, J.C. (2009) Detection of irregular, transient fMRI activity in normal controls using 2dTCA: Comparison to event-related analysis using known timing. Human brain mapping 30:3393-3405.

Morgan, V.L., Gore, J.C. \& Abou-Khalil, B. (2007) Cluster analysis detection of functional MRI activity in temporal lobe epilepsy. Epilepsy research 76:22-33.

Morgan, V.L., Gore, J.C. \& Abou-Khalil, B. (2010) Functional epileptic network in left mesial temporal lobe epilepsy detected using resting fMRI. Epilepsy research 88:168-178.

Morgan, V.L., Li, Y., Abou-Khalil, B. \& Gore, J.C. (2008) Development of 2dTCA for the detection of irregular, transient BOLD activity. Human brain mapping 29:57-69.

Morgan, V.L., Price, R.R., Arain, A., Modur, P. \& Abou-Khalil, B. (2004) Resting functional MRI with temporal clustering analysis for localization of epileptic activity without EEG. Neuroimage 21:473-481.

Moritz, C.H., Carew, J.D., McMillan, A.B. \& Meyerand, M.E. (2005) Independent component analysis applied to self-paced functional MR imaging paradigms. Neuroimage 25:181-192.

Morgan, V.L., Rogers, B.P., Sonmezturk, H.H., Gore, J.C. \& Abou-Khalil, B. (2011) Cross hippocampal influence in mesial temporal lobe epilepsy measured with high temporal resolution functional Magnetic Resonance Imaging. Epilepsia in press.

Neill, J.C., Liu, Z., Mikati, M. \& Holmes, G.L. (2005) Pilocarpine seizures cause agedependent impairment in auditory location discrimination. J. Exp. Anal. Behav. 84:357-370.

Norden, A.D. \& Blumenfeld, H. (2002) The role of subcortical structures in human epilepsy. Epilepsy Behav 3:219-231.

Ogawa, S., Lee, T.M., Nayak, A.S. \& Glynn, P. (1990) Oxygenation-sensitive contrast in magnetic-resonance image of rodent brain at high magnetic-fields Magnet Reson Med 14:68-78.

Park, S.P., Hwang, Y.H., Lee, H.W., Suh, C.K., Kwon, S.H. \& Lee, B.I. (2008) Long-term cognitive and mood effects of zonisamide monotherapy in epilepsy patients. Epilepsy Behav. 12:102-108.

Pelletier, I., Sauerwein, H.C., Lepore, F., Saint-Amour, D. \& Lassonde, M. (2007) Noninvasive alternatives to the Wada test in the presurgical evaluation of language and memory functions in epilepsy patients. Epileptic Disord 9:111-126.

Pereira, F.R.S., Alessio, A., Sercheli, M.S., Pedro, T., Bilevicius, E., Rondina, J.M., Ozelo, H.F.B., Castellano, G., Covolan, R.J.M., Damasceno, B.P. \& Cendes, F. (2010) Asymmetrical hippocampal connectivity in mesial temporal lobe epilepsy: evidence from resting state fMRI. BMC Neuroscience 11:66. 
Rabin, M.L., Narayan, V.M., Kimberg, D.Y., Casasanto, D.J., Glosser, G., Tracy, J.I., French, J.A., Sperling, M.R. \& Detre, J.A. (2004) Functional MRI predicts post-surgical memory following temporal lobectomy. Brain 127:2286-2298.

Raichle, M.E., MacLeod, A.M., Snyder, A.Z., Powers, W.J., Gusnard, D.A. \& Shulman, G.L. (2001) A default mode of brain function. Proceedings of the National Academy of Sciences of the United States of America 98:676-682.

Ramsey, N.F., Sommer, I.E.C., Rutten, G.J. \& Kahn, R.S. (2001) Combined analysis of language tasks in fMRI improves assessment of hemispheric dominance for language functions in individual subjects. Neuroimage 13:719-733.

Reitan, R.M. \& Wolfson, D. (1995) Category Test and Trail Making Test as Measures of Frontal-Lobe Functions. Clin. Neuropsychol. 9:50-56.

Richardson, M.P., Strange, B.A., Duncan, J.S. \& Dolan, R.J. (2006) Memory fMRI in left hippocampal sclerosis - Optimizing the approach to predicting postsurgical memory. Neurology 66:699-705.

Richardson, M.P., Strange, B.A., Thompson, P.J., Baxendale, S.A., Duncan, J.S. \& Dolan, R.J. (2004) Pre-operative verbal memory fMRI predicts post-operative memory decline after left temporal lobe resection. Brain 127:2419-2426.

Rodionov, R., De Martino, F., Laufs, H., Carmichael, D.W., Formisano, E., Walker, M., Duncan, J.S. \& Lemieux, L. (2007) Independent component analysis of interictal fMRI in focal epilepsy: comparison with general linear model-based EEGcorrelated fMRI. Neuroimage 38:488-500.

Roebroeck, A., Formisano, E. \& Goebel, R. (2005) Mapping directed influence over the brain using Granger causality and fMRI. Neuroimage 25:230-242.

Rogers, B.P., Katwal, S.B., Morgan, V.L., Asplund, C.L. \& Gore, J.C. (2010) Functional MRI and multivariate autoregressive models. Magnetic Resonance Imaging 28:1058-1065.

Rogers, B.P., Morgan, V.L., Newton, A.T. \& Gore, J.C. (2007) Assessing functional connectivity in the human brain by fMRI. Magn Reson Imaging 25:1347-1357.

Rutten, G.J.M., Ramsey, N.F., van Rijen, P.C., Alpherts, W.C. \& van Veelen, C.W.M. (2002a) fMRI-determined language lateralization in patients with unilateral or mixed language dominance according to the Wada test. Neuroimage 17:447-460.

Rutten, G.J.M., Ramsey, N.F., van Rijen, P.C., Noordmans, H.J. \& van Veelen, C.W.M. (2002b) Development of a functional magnetic resonance imaging protocol for intraoperative localization of critical temporoparietal language areas. Ann Neurol 51:350-360.

Salek-Haddadi, A., Lemieux, L., Merschhemke, M., Friston, K.J., Duncan, J.S. \& Fish, D.R. (2003) Functional magnetic resonance imaging of human absence seizures. Ann Neurol 53:663-667.

Seo, J.G., Lee, D.I., Hwang, Y.H., Lee, H.W., Jung, D.K., Suh, C.K., Kwon, S.H. \& Park, S.P. (2007) Comparison of cognitive effects of lamotrigine and oxcarbazepine in epilepsy patients. J. Clin. Neurol. 3:31-37.

Shukla, D.K., Keehn, B. \& Muller, R.A. (2010) Regional homogeneity of fMRI time series in autism spectrum disorders. Neuroscience letters 476:46-51.

Shulman, G.L., McAvoy, M.P., Cowan, M.C., Astafiev, S.V., Tansy, A.P., d'Avossa, G. \& Corbetta, M. (2003) Quantitative analysis of attention and detection signals during visual search. J. Neurophysiol. 90:3384-3397. 
Shulman, R.G., Rothman, D.L., Behar, K.L. \& Hyder, F. (2004) Energetic basis of brain activity: implications for neuroimaging. Trends Neurosci. 27:489-495.

Sidtis, J.J. (2007) Some problems for representations of brain organization based on activation in functional imaging. Brain Lang. 102:130-140.

Siegel, A.M. (2004) Presurgical evaluation and surgical treatment of medically refractory epilepsy. Neurosurgical review 27:1-18; discussion 19-21.

Spencer, S.S. \& Bautista, R.E. (2000) Functional neuroimaging in localization of the ictal onset zone. Advances in neurology 83:285-296.

Stanberry, L., Nandy, R. \& Cordes, D. (2003) Cluster analysis of fMRI data using dendrogram sharpening. Human brain mapping 20:201-219.

Suarez, R.O., Whalen, S., O'Shea, J.P. \& Golby, A.J. (2008) A Surgical Planning Method for Functional MRI Assessment of Language Dominance: Influences from Threshold, Region-of-Interest, and Stimulus Mode. Brain Imaging Behav. 2:59-73.

Szaflarski, J.P., DiFrancesco, M., Hirschauer, T., Banks, C., Privitera, M.D., Gotman, J. \& Holland, S.K. (2010) Cortical and subcortical contributions to absence seizure onset examined with EEG/fMRI. Epilepsy Behav. 18:404-413.

Vaudano, A.E., Laufs, H., Kiebel, S.J., Carmichael, D.W., Hamandi, K., Guye, M., Thornton, R., Rodionov, R., Friston, K.J., Duncan, J.S. \& Lemieux, L. (2009) Causal Hierarchy within the Thalamo-Cortical Network in Spike and Wave Discharges. Plos One 4.

Verleger, R., Lefebre, C., Wieschemeyer, R. \& Kompf, D. (1997) Event-related potentials suggest slowing of brain processes in generalized epilepsy and alterations of visual processing in patients with partial seizures. Cognit. Brain Res. 5:205-219.

Vlooswijk, M.C.G., Jansen, J.F.A., Majoie, H.J.M., Hofman, P.A.M., de Krom, M.C.T.F.M., Aldenkamp, A.P. \& Backes, W.H. (2010) Functional connectivity and language impairment in cryptogenic localization-related epilepsy. Neurology 75:395-402.

Voets, N.L., Adcock, J.E., Stacey, R., Hart, Y., Carpenter, K., Matthews, P.M. \& Beckmann, C.F. (2009) Functional and Structural Changes in the Memory Network Associated with Left Temporal Lobe Epilepsy. Human brain mapping 30:4070-4081.

Wagner, K., Frings, L., Halsband, U., Everts, R., Buller, A., Spreer, J., Zentner, J. \& SchulzeBonhage, A. (2007) Hippocampal functional connectivity reflects verbal episodic memory network integrity. Neuroreport 18:1719-1723.

Waites, A.B., Briellmann, R.S., Saling, M.M., Abbott, D.F. \& Jackson, G.D. (2006) Functional connectivity networks are disrupted in left temporal lobe epilepsy. Ann Neurol 59:335-343.

Wang, L.Q., Song, M., Jiang, T.Z., Zhang, Y.T. \& Yu, C.S. (2011) Regional homogeneity of the resting-state brain activity correlates with individual intelligence. Neuroscience letters 488:275-278.

Wiebe, S., Blume, W.T., Girvin, J.P. \& Eliasziw, M. (2001) A randomized, controlled trial of surgery for temporal-lobe epilepsy. The New England journal of medicine 345:311-318.

Wong, C.H., Bleasel, A., Wen, L.F., Eberl, S., Byth, K., Fulham, M., Somerville, E. \& Mohamed, A. (2010) The topography and significance of extratemporal hypometabolism in refractory mesial temporal lobe epilepsy examined by FDGPET. Epilepsia 51:1365-1373.

Xiong, J., Parsons, L.M., Gao, J.H. \& Fox, P.T. (1999) Interregional connectivity to primary motor cortex revealed using MRI resting state images. Human brain mapping 8:151156. 
Yan, C.G., Liu, D.Q., He, Y., Zou, Q.H., Zhu, C.Z., Zuo, X.N., Long, X.Y. \& Zang, Y.F. (2009) Spontaneous Brain Activity in the Default Mode Network Is Sensitive to Different Resting-State Conditions with Limited Cognitive Load. Plos One 4.

Yang, H., Long, X.Y., Yang, Y.H., Yan, H., Zhu, C.Z., Zhou, X.P., Zang, Y.F. \& Gong, Q.Y. (2007) Amplitude of low frequency fluctuation within visual areas revealed by resting-state functional MRI. Neuroimage 36:144-152.

Yu, L. \& Blumenfeld, H. (2009) Theories of Impaired Consciousness in Epilepsy. Disorders of Consciousness 1157:48-60.

Zang, Y.F., He, Y., Zhu, C.Z., Cao, Q.J., Sui, M.Q., Liang, M., Tian, L.X., Jiang, T.Z. \& Wang, Y.F. (2007) Altered baseline brain activity in children with ADHD revealed by resting-state functional MRI. Brain Dev. 29:83-91.

Zang, Y.F., Jiang, T.Z., Lu, Y.L., He, Y. \& Tian, L.X. (2004) Regional homogeneity approach to fMRI data analysis. Neuroimage 22:394-400.

Zhang, Z., Lu, G., Zhong, Y., Tan, Q., Liao, W., Chen, Z., Shi, J. \& Liu, Y. (2009a) Impaired perceptual networks in temporal lobe epilepsy revealed by resting fMRI. Journal of neurology 256:1705-1713.

Zhang, Z., Lu, G., Zhong, Y., Tan, Q., Yang, Z., Liao, W., Chen, Z., Shi, J. \& Liu, Y. (2009b) Impaired attention network in temporal lobe epilepsy: a resting FMRI study. Neuroscience letters 458:97-101.

Zhang, Z.Q., Lu, G.M., Zhong, Y., Tan, Q.F., Liao, W., Wang, Z.G., Wang, Z.Q., Li, K., Chen, H.F. \& Liu, Y.J. (2010a) Altered spontaneous neuronal activity of the default-mode network in mesial temporal lobe epilepsy. Brain Res. 1323:152-160.

Zhang, Z.Q., Lu, G.M., Zhong, Y.A., Tan, Q.F., Chen, H.F., Liao, W., Tian, L., Li, Z.H., Shi, J.X. \& Liu, Y.J. (2010b) FMRI Study of Mesial Temporal Lobe Epilepsy Using Amplitude of Low-Frequency Fluctuation Analysis. Human brain mapping 31:18511861.

Zuo, X.N., Kelly, C., Adelstein, J.S., Klein, D.F., Castellanos, F.X. \& Milham, M.P. (2010) Reliable intrinsic connectivity networks: Test-retest evaluation using ICA and dual regression approach. Neuroimage 49:2163-2177. 


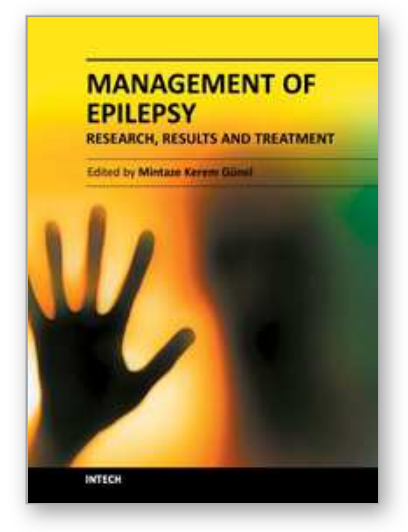

\author{
Management of Epilepsy - Research, Results and Treatment \\ Edited by Prof. Mintaze Kerem GÃ $1 / 4 n e l$
}

ISBN 978-953-307-680-5

Hard cover, 194 pages

Publisher InTech

Published online 15, September, 2011

Published in print edition September, 2011

Epilepsy is one of the most common neurological disorders, with a prevalence of 4-10/1000. The book contains the practical methods to approaching the classification and diagnosis of epilepsy, and provides information on management. Epilepsy is a comprehensive book which guides the reader through all aspects of epilepsy, both practical and academic, covering all aspects of diagnosis and management of children with epilepsy in a clear, concise, and practical fashion. The book is organized so that it can either be read cover to cover for a comprehensive tutorial or be kept desk side as a reference to the epilepsy. Each chapter introduces a number of related epilepsy and its diagnosis, treatment and co-morbidities supported by examples. Included chapters bring together valuable materials in the form of extended clinical knowledge from practice to clinic features.

\title{
How to reference
}

In order to correctly reference this scholarly work, feel free to copy and paste the following:

Victoria L. Morgan and Bassel Abou-Khalil (2011). Investigations of Brain Network Alterations in Epilepsy Using Functional Magnetic Resonance Imaging, Management of Epilepsy - Research, Results and Treatment, Prof. Mintaze Kerem GÃ $1 / 4$ nel (Ed.), ISBN: 978-953-307-680-5, InTech, Available from:

http://www.intechopen.com/books/management-of-epilepsy-research-results-and-treatment/investigations-ofbrain-network-alterations-in-epilepsy-using-functional-magnetic-resonance-imaging

\section{INTECH}

open science | open minds

\section{InTech Europe}

University Campus STeP Ri

Slavka Krautzeka 83/A

51000 Rijeka, Croatia

Phone: +385 (51) 770447

Fax: +385 (51) 686166

www.intechopen.com

\section{InTech China}

Unit 405, Office Block, Hotel Equatorial Shanghai

No.65, Yan An Road (West), Shanghai, 200040, China

中国上海市延安西路65号上海国际贵都大饭店办公楼 405 单元

Phone: +86-21-62489820

Fax: $+86-21-62489821$ 
(C) 2011 The Author(s). Licensee IntechOpen. This chapter is distributed under the terms of the Creative Commons Attribution-NonCommercialShareAlike-3.0 License, which permits use, distribution and reproduction for non-commercial purposes, provided the original is properly cited and derivative works building on this content are distributed under the same license. 